\title{
Assessment of the grinding wheel active surface condition using SEM and image analysis techniques
}

\author{
Wojciech Kapłonek • Krzysztof Nadolny
}

Received: 11 July 2011/Accepted: 10 April 2012/Published online: 7 June 2013

(C) The Author(s) 2013. This article is published with open access at Springerlink.com

\begin{abstract}
The grinding wheel active surface (GWAS) condition assessment after the grinding processes is one of the crucial elements of diagnostics of abrasive tools used in modern production industry. At present there exist a number of measurement methods which facilitate such evaluation (e.g. stylus, optical, pneumatic). These may include also imaging methods using the scanning electron microscopy (SEM). This paper presents and discusses a proposal for obtaining additional information concerning the GWAS condition based on the acquired, properly processed, and computer-analyzed SEM micrographs. In the experimental investigations SEM micrographs of the selected GWAS areas with abraded vertexes and microsmearings of the abrasive grains active vertexes, macrosmearings of grains and intergranular spaces, as well as intergranular spaces filled with sulfur introduced during the impregnation process were acquired. For acquisition the scanning electron microscope JSM-5500LV by JEOL Ltd. (Japan) was used. Image analysis of selected GWAS areas was carried out by specialized research environment Image-Pro ${ }^{\circledR}$ Plus 5.1. It was concluded that the applied
\end{abstract}

Technical Editor: Alexandre Abrão.

W. Kapłonek ( $\square)$

Subject Group of Metrology and Quality, Department of Production Engineering, Faculty of Mechanical Engineering, Koszalin University of Technology, Racławcka 15-17, 75-620 Koszalin, Poland

e-mail: wojciech.kaplonek@tu.koszalin.pl

K. Nadolny

Department of Production Engineering, Faculty of Mechanical Engineering, Koszalin University of Technology,

Racławcka 15-17, 75-620 Koszalin, Poland

e-mail: krzysztof.nadolny@tu.koszalin.pl techniques were highly useful and could complement the typically used ones, especially in complex tests.

Keywords Scanning electron microscope - Image processing and analysis - Grinding wheel active surface . Abrasive tools diagnostics

\section{Introduction}

Assessment of the grinding wheel active surface (GWAS) $[2,6,16,22]$ constitutes one of the crucial diagnostic problems concerning abrasive tools used in modern machining processes [23]. It allows for proper assessment of the grinding wheel durability period and for wear analysis of its component mechanisms. The GWAS condition after completion of the machining process is a primary, and invaluable, source of information (concerning, e.g. modification of the tool structure or of the process itself) which influences the course, and effects, of the machining process. To successfully interpret the results obtained from the machining process, a proper assessment, either quantitative or qualitative, of the GWAS's condition should be carried out. The first case is related to a general visual analysis of the abrasive tool surface (e.g. detection of defects and identification of areas smeared with the machined material). In the latter case the analysis leads to determination of the parameters describing the examined surface characteristics. Such an analysis allows for, among other things, calculation of the number of abrasive grain active vertexes, the porous capacity (free intergranular spaces), and the level of GWAS porosity.

Numerous measurement methods are used in the assessment of the GWAS condition [5, 8, 18], the standard approach is to use the stylus profilometer method [1,20], 
and with their help, a large number of parameters describing the GWAS condition can be obtained utilizing a registered profile, or microtopography. This may be a useful assessment criterion, especially in routine measurements realized in laboratory or industrial conditions. In many research applications, one measurement method may, however, be insufficient. In cases of special interest, a few methods should be used, especially if the assessment is to be thorough. Stylus methods can thus be supported by optic (e.g. laser scatterometry [11, 14]), optical profilometry $[15,19]$, interferential microscopy $[13,26]$, confocal laser scanning microscopy [7, 21], or imaging methods (e.g. scanning electron microscopy, SEM [3, 20]). The latter of these methods, in this context, is the most frequently used because of its various advantages, including high angular resolution, large depth of field, high-quality image capture, the possibility to change magnification and scan large surfaces quickly or to obtain a diffraction image (identifying the crystalline structure) and finally, performing elemental analysis of the material using the energy dispersive X-ray spectroscope module (EDS) coupled with the microscope.

\section{Assessment of the GWAS condition after the grinding process}

The GWAS during the grinding process is influenced by the tool component wear processes: those relating to the abrasive grains and the bond. The most important wear processes include the abrasive and fatigue resistance wear $[9,10,17,25]$, which can be further divided as follows:

- abrasive wear of the abrasive grains active vertexes;

- abrasive wear of the bond at the point of contact with the workpiece;

- fatigue wear of the abrasive grains resultant from mechanical and thermal shock loads;

- fatigue wear of the bond-bridges;

- fatigue wear on the phase border between the abrasive grain and the bond-bridge;

- smearing of the grains vertexes and the intergranular spaces with ground elements from the workpiece.

What occurs most frequently in the optimized machining processes is the progressive abrasion of the active abrasive grains vertexes, which is accompanied by bond abrasion. In the case of high efficiency grinding processes, the grinding wheel is subject to considerable greater mechanical and thermal strain. As a result, the fatigue wear can become the dominant type. It is usually characterized by intensive volumetric wear of the grinding wheel and changes to the tool diameter.
The optical properties of SEM micrograph analysis make it the most useful method in assessing the results of abrasive grain, and bond abrasive, wear. It also offers the possibility to assess the smearing of the GWAS with workpiece chips and other ground products (crumbled abrasive grains and bond).

The GWAS smearing usually occurs when there is insufficient insertion of coolant into the contact area between grinding wheel and workpiece. Temperature increase in the grinding zone, caused by insufficient cooling and clearing of the GWAS, results in the chips adhering to the grinding wheel surface. This phenomenon is related mainly to grinding materials with poor heat conductivity. In especially hard GWAS operating conditions, large surfaces can be smeared, including abrasive grains and the intergranular spaces. The reason for their appearance is most often excessive material removal rate during the grinding process, grinding wheel wear, as well as small intergranular spaces which do not allow for removal of ground products to an area outwith the machining zone and do not supply enough access points to the grinding zone, to aid insertion of liquid coolant.

Another case, in which SEM micrograph analysis can be successfully used, is in the assessment of the surface condition of tools with modified surfaces or structures. An example of such a modification is impregnating the grinding wheels with anti-adhesive compounds to prevent, or limit, the GWAS smearing phenomenon [4, 17, 24].

This paper presents analyses of some exemplary SEM micrographs of the GWAS after the internal cylindrical grinding process. The micrographs were selected to represent the above-mentioned potential applications of this technique. As a result, an analysis for the GWAS micrographs with the following characteristic elements was developed:

- abraded abrasive grains vertexes;

- microsmearings of the abrasive grains active vertexes;

- macrosmearings of the abrasive grains and intergranular spaces;

- with the active substance (sulfur) introduced into the grinding wheel mass in the impregnation process.

\section{Experimental investigations}

The experimental investigations were mainly undertaken to check the possibility of obtaining additional information concerning the GWAS condition on the basis of the acquired, properly processed, and computer-analyzed SEM micrographs. Moreover, the investigations were also aimed at analyzing and selecting the proper functions of the 
Table 1 General characteristics of the grinding wheels used in experimental investigations-technical designation

\begin{tabular}{|c|c|c|}
\hline $\begin{array}{l}\text { Sample } \\
\text { No. }\end{array}$ & \multicolumn{2}{|l|}{ Technical designation } \\
\hline 1 & \multicolumn{2}{|c|}{$1-35 \times 10 \times 10-S G / F 46$ K7VDG } \\
\hline 2 & \multicolumn{2}{|c|}{$1-35 \times 20 \times 10-\mathrm{SG} / \mathrm{F} 46 \mathrm{G} 10 \mathrm{VTO}$} \\
\hline 3 & $\begin{array}{l}1-35 \times 20 \times 10-\mathrm{SG} / \mathrm{F} 46 \\
\mathrm{~K} 7 \mathrm{VDG} 70 \% / 99 \mathrm{~A} / \mathrm{F} 80 \\
\text { I7VDG } 30 \%\end{array}$ & $\begin{array}{l}\text { Zone-diversified structure } \\
\text { grinding wheel—rough } \\
\text { grinding zone of the } \\
\text { grinding wheel active } \\
\text { surface made of abrasive } \\
\text { grains size } 46 \text { was assessed }\end{array}$ \\
\hline 4 & $\begin{array}{l}1-35 \times 20 \times 10-\mathrm{SG} / \mathrm{F} 46 \\
\text { G10VTO }\end{array}$ & After sulfurization \\
\hline
\end{tabular}

Table 2 General characteristics of the grinding wheels used in experimental investigations-analyzed specific elements of the GWAS

\begin{tabular}{|c|c|c|}
\hline $\begin{array}{l}\text { Sample } \\
\text { No. }\end{array}$ & Assessed objects & $\begin{array}{l}\text { Characteristic features of the } \\
\text { GWAS }\end{array}$ \\
\hline 1 & $\begin{array}{l}\text { GWAS after internal } \\
\text { cylindrical plunge } \\
\text { grinding with oscillations } \\
\text { (workpiece: } 100 \mathrm{Cr} 6 \text { steel) }\end{array}$ & $\begin{array}{l}\text { Dulled vertexes of active } \\
\text { abrasive grains }\end{array}$ \\
\hline 2 & $\begin{array}{l}\text { GWAS after internal } \\
\text { cylindrical plunge } \\
\text { grinding (workpiece: } \\
\text { INCONEL }^{\circledR} \text { alloy 600) }\end{array}$ & $\begin{array}{l}\text { Microsmearings of active } \\
\text { abrasive grains vertexes }\end{array}$ \\
\hline 3 & $\begin{array}{l}\text { GWAS after single-pass } \\
\text { internal cylindrical } \\
\text { grinding (workpiece: } \\
\text { 100Cr6 steel) }\end{array}$ & $\begin{array}{l}\text { Macrosmearings of abrasive } \\
\text { grain vertexes and } \\
\text { intergranular spaces }\end{array}$ \\
\hline 4 & $\begin{array}{l}\text { GWAS after internal } \\
\text { cylindrical plunge } \\
\text { grinding (workpiece: } \\
\text { Titanium Grade } 2^{\circledR} \text { ) }\end{array}$ & $\begin{array}{l}\text { Intergranular spaces filled } \\
\text { by sulfur }\end{array}$ \\
\hline
\end{tabular}

Image-Pro ${ }^{\circledR}$ Plus 5.1 environment for realization of the above-mentioned procedures.

\section{Characteristics of the samples used in the investigations}

The SEM micrographs of the GWAS with ceramic bond and microcrystalline sintered corundum grains underwent the experimental investigations. Four grinding wheels, whose detailed descriptions are included in Tables 1 and 2, were selected for the investigations.

\section{Characteristics of the samples used in the investigations}

Micrographs were acquired for the above-described samples. The acquisition was carried out for selected GWAS areas where the following elements could be found: abraded vertexes and microsmearings of the abrasive grains active vertexes, macrosmearings of grains and intergranular spaces, as well as intergranular spaces filled with sulfur introduced during the impregnation process. Before acquisition, the samples were surface-cleaned with compressed air and then placed on a specimen stage located in the vacuum chamber of the microscope.

The scanning electron microscope JSM-5500LV by JEOL Ltd. (Japan) was used for acquisition. This device was characterized by the following parameters: magnification range from $18 \times$ to $300,000 \times$, resolution from $4.0 \mathrm{~nm}$ (high vacuum mode) to $5.0 \mathrm{~nm}$ (low vacuum mode), with accelerating voltage $30 \mathrm{kV}$, pressure in the vacuum chamber from 10 to $270 \mathrm{~Pa}$, accelerating voltage from 0.5 to $30 \mathrm{kV}$. $50 \times, 100 \times, 500 \times$
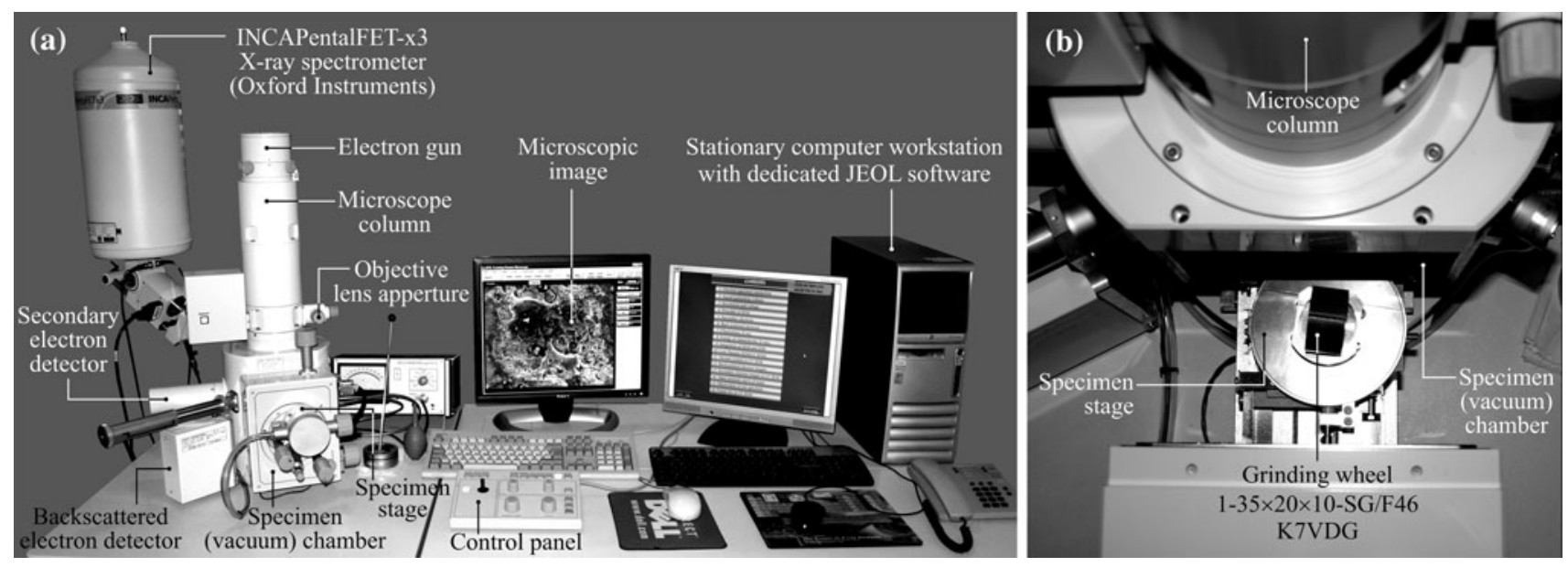

Fig. 1 The JEOL JSM 5500LV scanning electron microscope produced by JEOL Ltd.: a general view of microscope, $\mathbf{b}$ view of the grinding wheel prepared for assessment placed on the specimen stage 


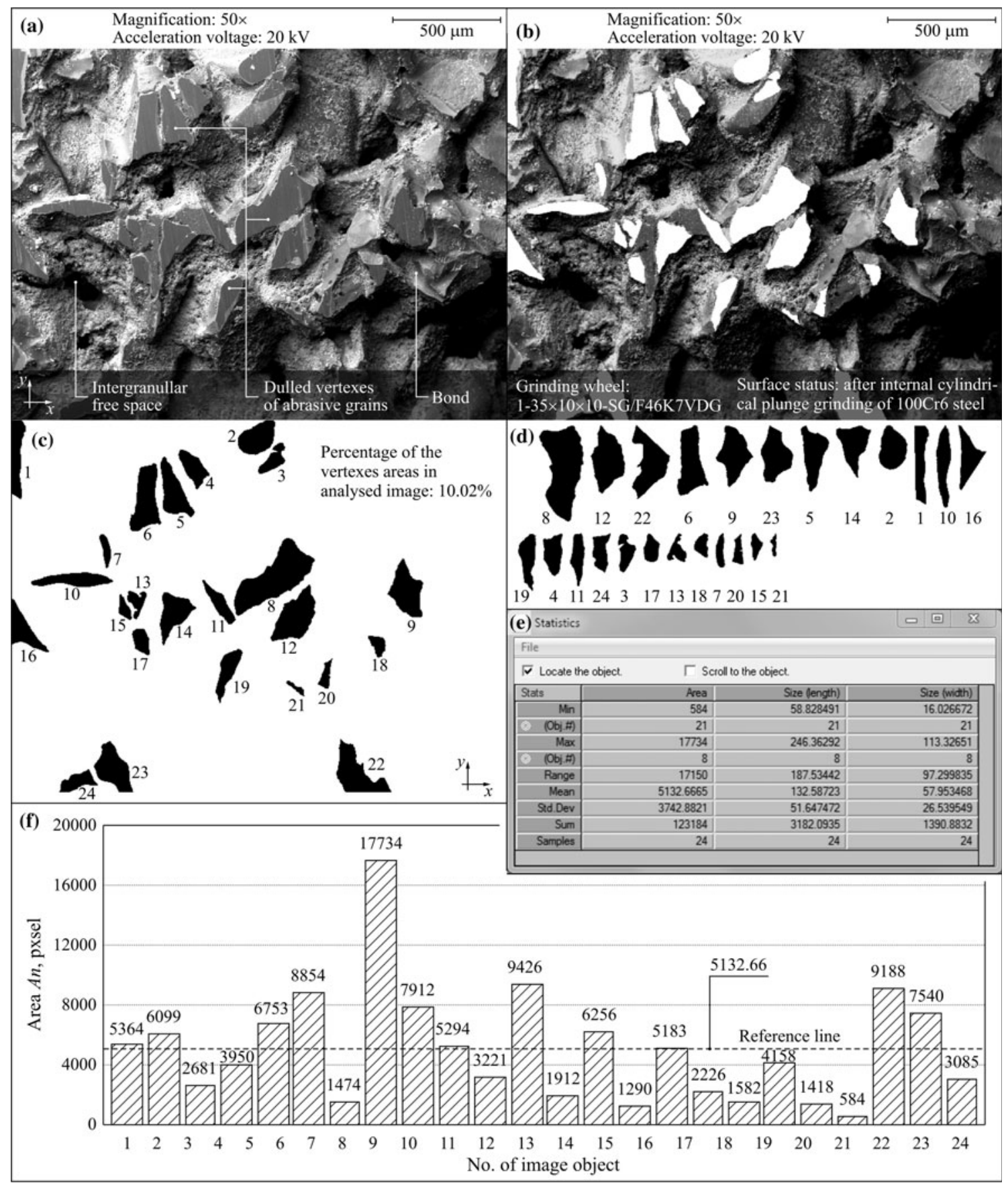

Fig. 2 The results of image analysis carried out in the Image-Pro ${ }^{\circledR}$ Plus 5.1 software for sample No. 1: a input image with the selected specific elements of the GWAS, b image from a with mask, which contained selected areas (objects) corresponding to the dulled vertexes of active abrasive grains $\mathbf{c}$ image of the mask with the determined number of areas (objects) corresponding to the dulled

magnifications were used during acquisition, with accelerating voltage ranging from 15 to $20 \mathrm{kV}$. The acquired micrographs were characterized by the following parameters: resolution 1,280 × 960 pixels, 8-bit vertexes of active abrasive grains (function Count/Size), d areas (objects) from $\mathbf{c}$, classified according to the size of the area, $\mathbf{e}$ window of the Statistics function with determined geometric parameters from $\mathbf{c}$ and $\mathbf{f}$ column diagram showing the values of the area for particular areas (objects) in the analyzed input image in relation to the mean values (reference line)

color depth, gray-color mode, saving format *.bmp. Fig. 1 presents the general view of the scanning electron microscope JSM-5500LV by JEOL Ltd., used in the investigations. 


\section{Characteristics of the samples used in the investigations}

This section presents the analyses carried out on the four selected micrographs acquired during the experimental investigations. All of the operations on the images were realized using a specialized research environment ImagePro ${ }^{\circledR}$ Plus 5.1 by Media Cybernetics. The Authors have already used it before in similar investigations $[11,12,14]$.

Figure 2 depicts the results of the image analysis carried out on sample No. 1. In this case it was a grinding wheel with technical designation $1-35 \times 10 \times 10-\mathrm{SG} / \mathrm{F} 46$ K7VDG. The tool was used for internal cylindrical plunge grinding with oscillation in 100Cr6 steel. A micrograph depicting the abraded abrasive grains active vertexes was registered for the GWAS. The image captured a GWAS fragment measuring $5.12 \times 3.84 \mathrm{~mm}$, for which fragments with abraded abrasive grains active vertexes were isolated using binarization. Thus, the obtained mask was mapped onto the input image (Fig. 2b) to check whether binarization was carried out in the correct way. Next, using the Count/Size function the software counted all of the dark areas (objects) in the analyzed image automatically (Fig. 2c). This operation allowed for determining the basic geometric parameters characteristic of the abraded abrasive grains active vertexes (i.e. the areas $A n$, length $l$ and width $w)$. The obtained values were presented statistically. For this purpose the Statistics function was used (Fig. 2e).
Moreover, all of the selected areas were also sorted according to their area size. The operation was carried out automatically by the Sorted Object Image function (Fig. 2d). The obtained values of one of the geometric parameters - the An area size, were compared for all of the selected areas (objects). The column diagram (Fig. 2f) includes a referential line which consists of the average area value for all the areas. The diagram analysis concluded that the areas were characterized by similar size, while area (object) No. 21 had the smallest $A n$, which was 504 pixels $\left(2,336 \mu \mathrm{m}^{2}\right)$, and area (object) No. 8 had the greatest value $A n=17,734$ pixels $\left(70,936 \mu \mathrm{m}^{2}\right)$. The abraded abrasive grains active vertexes areas consisted of $10.02 \%$ of the total area of the analyzed GWAS fragment.

Figure 3 presents the results of image analysis of sample No. 2-the grinding wheel with technical designation $1-35 \times 20 \times 10-\mathrm{SG} / \mathrm{F} 46$ G10VTO. It was used for internal cylindrical grinding in INCONEL $^{\circledR}$ alloy 600. In the GWAS micrograph three different-sized microsmearings of the abrasive grain vertexes can be observed. In these cases the analysis mostly consisted of determining the distance between the objects (microsmearings) visible in the image. Fragments, extracted from the input image (Fig. 3a) of size $5.12 \times 3.84 \mathrm{~mm}$, were magnified to make the details of microsmearings, in various areas of the analyzed surface, visible. After the binarization process, an image with three selected areas containing the microsmearings was obtained (Fig. 3b). Area values were calculated for these areas using

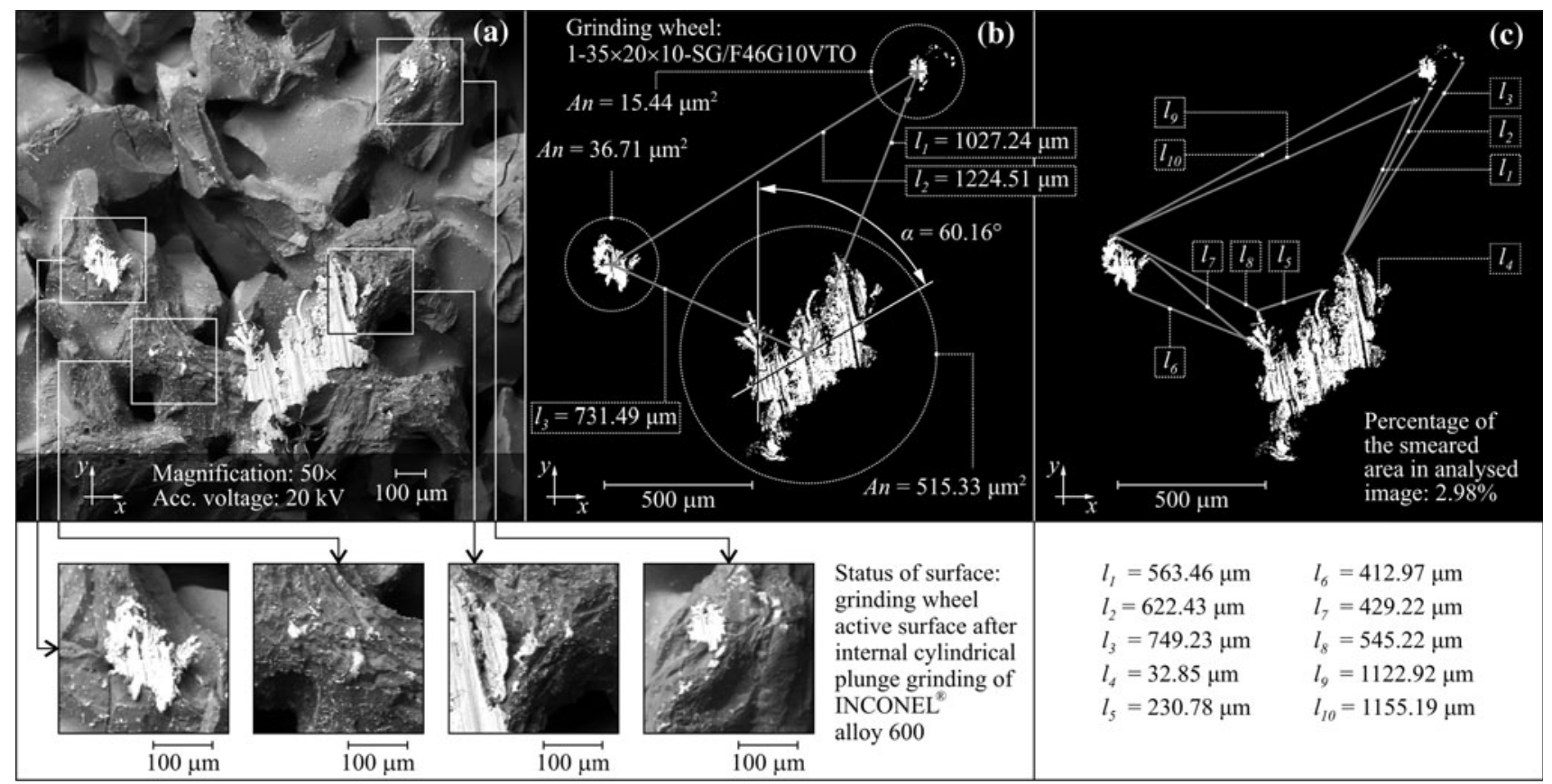

Fig. 3 The results of image analysis carried out in the Image-Pro ${ }^{\circledR}$ Plus 5.1 software for sample No. 2: a input image with selected microsmearing areas of the GWAS (additionally these were magnified and shown below), $\mathbf{b}$ image from $\mathbf{a}$ after the binarization process with determined values of the all microsmearing areas and distances from its center mass (function Count/Size), $\mathbf{c}$ determination of the distance from the selected microsmearing (function Measurement and Measure Distance) 

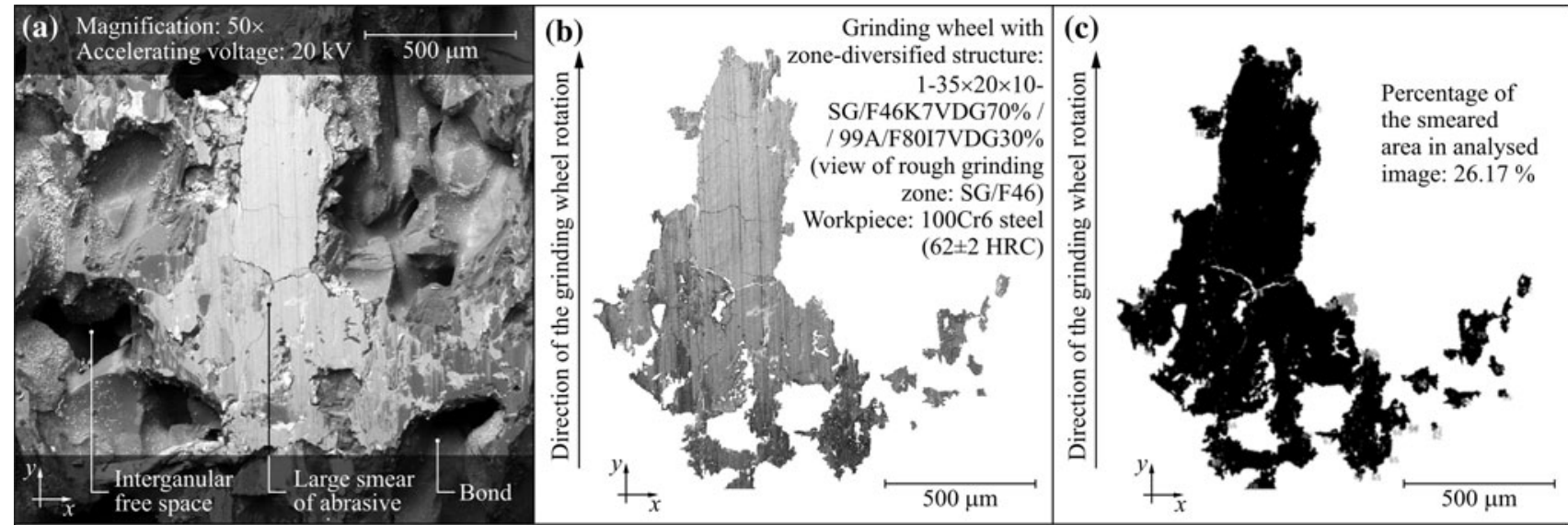

(d)

\begin{tabular}{|c|c|c|c|c|c|c|}
\hline Lp & Parameter & Interpretation & Value & Unit & Value & Unit \\
\hline 1 & Objects & The number of recognized objects in the image. & 70 & - & 70 & - \\
\hline 2 & Area $(A n)$ & $\begin{array}{l}\text { Parameter determined in automatic mode by counting the points of image } \\
\text { belong to the selected AOI. }\end{array}$ & 2330.37 & pixel & 9321.48 & $\mu \mathrm{m}^{2}$ \\
\hline 3 & Center X (mass) & Intensity weighted centroid X-position. & 398.96 & - & 1595.84 & - \\
\hline 4 & Center Y (mass) & Intensity weighted centroid Y-position. & 473.91 & - & 1895.64 & - \\
\hline 5 & Hole area $(A h)$ & Area of the holes within the object. & 166.01 & pixel & 664.04 & $\mu \mathrm{m}^{2}$ \\
\hline 6 & Holes & Number of holes within the object. & 7 & - & 7 & - \\
\hline 7 & Diameter $\left(d_{\max }\right)$ & $\begin{array}{l}\text { Length of longest line joining two points of object's outline and passing through } \\
\text { the centroid. }\end{array}$ & 17.16 & pixel & 68.64 & $\mu \mathrm{m}$ \\
\hline 8 & Diameter $\left(d_{\min }\right)$ & $\begin{array}{l}\text { Length of shortest line joining two points of object's outline and passing through } \\
\text { the centroid. }\end{array}$ & 6.96 & pixel & 27.84 & $\mu \mathrm{m}$ \\
\hline 9 & Perimeter $(P)$ & Length of the object's outline. & 61.26 & pixel & 245.04 & $\mu \mathrm{m}$ \\
\hline 10 & Size - length $(l)$ & Feret diameter (i.e. caliper length) along major axis of object. & 16.51 & pixel & 66.04 & $\mu \mathrm{m}$ \\
\hline 11 & Size - width $(w)$ & Feret diameter (i.e. caliper length) along minor axis of object. & 10.11 & pixel & 40.44 & $\mu \mathrm{m}$ \\
\hline
\end{tabular}

Fig. 4 The results of image analysis carried out in the Image-Pro ${ }^{\circledR}$ Plus 5.1 software for sample No. 3: a input image with selected specific elements of the GWAS, b extracted from a total smearing area with lateral areas (function Irregular AOI), c extracted smearing

the Count/Size function. The values obtained in pixels were converted into micrometers and mapped onto the image. Next, using the same function, the coordinates of the centers of mass of particular microsmearing areas and the distances between them were determined (Measurement and Measure Distance functions). Moreover, the angle of tilt of the area with the greatest microsmearing in relation to the grinding wheel axis was calculated. Below (Fig. 3c) are presented the exemplary measurements of the distances between the selected points on the microsmearing areas. The last stage of the performed analysis determined the share of the microsmearing areas in the whole assessed image expressed in percentage terms. The share was $2.98 \%$.

Figure 4 presents the results of the image analysis carried out for sample No. 3. It was a grinding wheel with zone-diversified structure with the technical designation $1-35 \times 20 \times 10-$ SG/F46 K7VDG70 \%/99A/F80 I7VDG30 $\%$. The active surface of the rough grinding wheel, made from SG grains sized 46, underwent the investigations. The grinding wheel was used in the single-pass internal area from $\mathbf{b}$ after the binarization, $\mathbf{d}$ characteristics and the numerical values of selected geometrical parameters determined in automatic mode (function Count/Size)

cylindrical grinding of the bearing rings made from steel $100 \mathrm{Cr} 6$. A vast area of macrosmearing of the abrasive grain vertexes and intergranular spaces is visible in the central part of the SEM micrograph acquired for this grinding wheel. The central fragment of the macrosmearing area, and small-sized areas located on its lower right side, were allocated from an image measuring $5.12 \times 3.84 \mathrm{~mm}$ acquired for sample No. 3, using the Irregular AOI function (Fig. 4b).

The allocation allowed for complete presentation of the macrosmearing area. Moreover, it facilitated determination of the direction in which the abrasive tool rotated, by observing the marks present upon its surface. After the binarization process, the above-mentioned image (Fig. 4c) was used to determine a number of geometric parameters. The parameter description and the automatically obtained (Count/Size function) values are presented in the diagram (Fig. 4d). In this case the analysis consisted mostly in determining a large number of geometric parameters describing the GWAS macrosmearing area. Image-Pro ${ }^{\circledR}$ Plus 5.1 software allows for calculation of over 30 


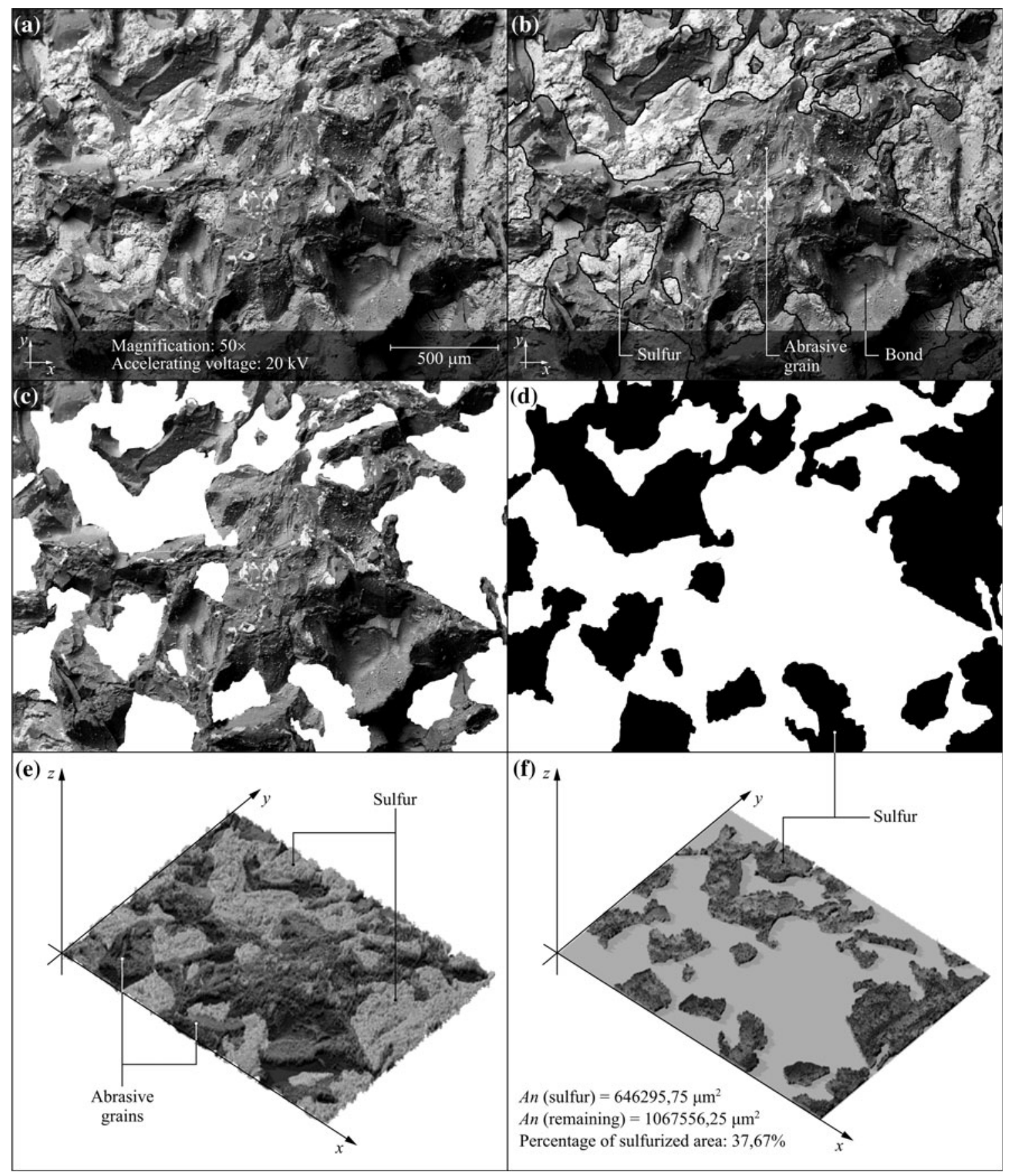

Fig. 5 The results of image analysis carried out in the Image-Pro ${ }^{\circledR}$ Plus 5.1 software for sample No. 4: a input image, b input image with extracted areas with sulfur (function Irregular AOI), $\mathbf{c}$ the image from b with extracted areas with sulfur (abrasive grains and binder are

geometric parameters. Only those selected parameters that have already been used by the authors (presented in the table given in Fig. 4d) were used during the analysis.

In case of further research, developing a universal parameter set (e.g. from eight to ten) which would be used for geometric description of, among other things, a surface with visible smearings will be considered. The end stage visible), d image from c after the binarization process, e 3D visualization of the GWAS generated from a includes areas with, and without, the sulfur, f 3D visualization of the GWAS generated from a with visible numerous areas containing sulfur

analysis of sample No. 3 determined the macrosmearing share in the whole assessed image in percentage terms, which was $26.17 \%$.

Figure 5 presents the results of image analysis carried out for sample No. 4. In this case it was a grinding wheel with technical designation $1-35 \times 20 \times 10-$ SG/F46 G10VTO. The tool underwent the process of impregnation 
with sulfur and was used in the internal cylindrical plunge grinding process of the Titanium Grade $2^{\circledR}$ alloy. The SEM micrograph acquired for such a surface presents vast intergranular spaces, devoid of sulfur and filled with sulfur.

Surface fragments containing sulfur (Fig. 5b) were allocated from an image measuring $5.12 \times 3.84 \mathrm{~mm}$ acquired for sample No. 4, using the Irregular AOI function. It can be observed that the GWAS areas containing sulfur were spread in an uneven manner in the analyzed image, which additionally hampered their visual observation. The sulfur color in images from the scanning microscope was similar to the background color, i.e. of the abrasive grains and the bond. Precise identification and selection of the sulfur-containing areas in the analyzed image was, therefore, necessary. After that, the sulfurcontaining areas were removed, leaving only the background (Fig. 5c). This allowed for more complete observation of the GWAS shaping and constituted the basis for carrying the binarization process. The post-binarization image (Fig. 5d) was used to carry out the analysis, i.e. calculate the summary area of the surface with and without sulfur. Moreover, just like in the case of previous analyses, the share of the sulfur-containing areas was also calculated in percentage terms. In this case it was $37.67 \%$. The presented analysis was extended with a 3D visualization of the GWAS, realized using the Surface Plot function. This function generates a quasi-spatial mapping of the flat twodimensional input image.

The 3D visualization of the GWAS acquired for sample No. 4 was presented in two variants. In the first variant (Fig. 5e) a visualization from Fig. 5b presenting the full grinding wheel area, i.e. both with and without sulfur, as well as the background, the abrasive grains, and the bond was generated. In the second variant (Fig. 5f), a visualization from the image in which the background was allocated (the abrasive grains and the bond), leaving a number of areas with sulfur, was generated. The presented visualizations could form an interesting supplement to the analyses carried out on 2D images. They emphasize certain surface features which are far more visible in the spatial view. This forms the basis for correct interpretation of the information the analyzed images contain.

\section{Conclusions}

The GWAS condition assessment, after the grinding processes have been completed, is one of the crucial diagnostic tests of abrasive tools used in modern production industries. At present there exist a number of measurement methods which facilitate such evaluation (stylus and optic profilometry, light scattering methods). Scanning microscopy turns out to be exceptionally useful in those interesting cases of thorough assessment which require a number of measurement methods. The great possibilities this technique offers enables the gathering of interesting data, related to the GWAS condition to occur, which could then complement, or supplement, the measurement results obtained using other methods. This is how the investigations presented in the work should be treated. Through a number of exemplary analyses the authors showed that method utilized is highly effective and useful and that it can diagnostically be applied in the case of abrasive tool surface analysis.

Acknowledgments This work was supported by the Polish Ministry of Science and Higher Education under Grant No. N503 214837. The Authors wish to thank Mr. Ryszard Gritzman, from the Central Laboratory of the Institute of Mechatronics, Nanotechnology and Vacuum Technique at Koszalin University of Technology, for acquisition of SEM micrographs.

Open Access This article is distributed under the terms of the Creative Commons Attribution License which permits any use, distribution, and reproduction in any medium, provided the original author(s) and the source are credited.

\section{References}

1. Butler DL et al (2002) The characterisation of grinding wheels using 3D surface measurement techniques. J Mater Process Technol 127(2):234-237

2. Davim JP (2010) Surface integrity in machining. Springer, London

3. Egerton RF (2005) Physical principles of electron microscopyan introduction to TEM, SEM and AEM. Springer Science + Buissnes Media, Inc., New York

4. El-Shall H, Somasundaran P (1984) Physico-chemical aspects of grinding: a review of use of additives. Powder Technol 38(3):275-293

5. Furutani K et al (2002) In-process measurement of topography change of grinding wheel by using hydrodynamic pressure. Int J Mach Tools Manuf 42(13): 1447-1453

6. Grote K-H, Antonsson EK (2009) Springer handbook of mechanical engineering. Springer Science + Business, LLC., New York

7. Miller PF et al (2010) Confocal laser scanning microscopy. Alphascript Publishing, Amsterdam

8. Hocken RJ et al (2005) Optical metrology of surfaces. Manuf Technol 54(2):169-183

9. Jackson MJ, Mills B (2004) Microscale wear of vitrified abrasive materials. J Mater Sci 39:2131-2143

10. Jackson MJ, Davim JP (2011) Machining with abrasives. Springer Science + Business, LLC, New York

11. Kapłonek W, Nadolny K (2011) Medição da dispersão da luz do laser usada para impedir empastamento no rebolo. Máquinas e Metais 47(544):104-117

12. Kapłonek W et al (2011) Dispersão da luz do laser na avaliação da rugosidade superficial de microacabamentos. Máquinas e Metais 47(548):96-109

13. Kapłonek W, Łukianowicz Cz (2012) Coherence correlation interferometry in surface topography measurements. In: Ivan Padron (ed) Recent interferometry applications in topography and astronomy. InTech, Rijeka, pp 1-26 
14. Kapłonek W et al (2012) Methodology of the assessment of the abrasive tool's active surface using laser scatterometry. Trans Can Soc Mech Eng 36(1):49-66

15. Kapłonek W et al (2012) High-accuracy surface topography measurements of abrasive tools using a 3D optical profiling system. Meas Autom Monit 58(5):443-447

16. Malkin S, Guo C (2008) Grinding technology: theory and applications of machining with abrasives. Industrial Press, Inc., New York

17. Marinescu ID et al (2004) Tribology of abrasive machining processes. William Andrew Publishing, Norwich

18. Mokbel AA, Maksoud TMA (2000) Monitoring of the condition of diamond grinding wheels using acoustic emission technique. J Mater Process Technol 101(1-3):292-297

19. Nadolny $\mathrm{K}$ et al (2011) Laser measurements of surface topography of abrasive tools using measurement system CLI2000. Przeglad Elektro- Techniczny (Electric Rev) 87(9a):24-27 (in Polish)

20. Nadolny K (2012) The method of assessment of the grinding wheel cutting ability in the plunge grinding. Central Eur J Eng 2(3):399-409
21. Nadolny K, Kapłonek W (2012) Confocal laser scanning microscopy for characterisation of surface microdiscontinuities of vitrified bonded abrasive tools. Int $\mathrm{J}$ Mech Eng Robot Res 1(1):14-29

22. Rowe WB (2009) Principles of modern grinding technology. William Andrew, Burlington

23. Słowiński B, Nadolny K (2010) Metodologia para análise do potencial de otimização de processos. Máquinas e Metais 46(536): 124-145

24. Turley DM (1985) Factors affecting surface finish when grinding titanium and a titanium alloy (Ti-6Al-4V). Wear 104(4):323-335

25. Wang J et al (1999) Abrasive technology: current development and applications I. World Scientific Publishing Co., Singapore

26. Yan L et al (2011) Three-dimension surface characterization of grinding wheel using white light interferometer. Int J Adv Manuf Technol 55(1-4):133-141 